\title{
Trauma Exposure and Posttraumatic Symptoms in Hawaii: Gender, Ethnicity, and Social Context
}

\author{
Bridget Klest and Jennifer J. Freyd \\ University of Oregon
}

\author{
Melissa Ming Foynes \\ VA Boston Healthcare System, Boston, Masssachusetts
}

\begin{abstract}
Eight-hundred and 33 members of an ethnically diverse longitudinal cohort study in Hawaii were surveyed about their personal exposure to several types of traumatic events, socioeconomic resources, and mental health symptoms. Results replicated findings from prior research that while men and women are exposed to similar rates of trauma overall, women report more exposure to traumas high in betrayal (HB), while men report exposure to more traumas lower in betrayal (LB). Trauma exposure was predictive of mental health symptoms, with neglect, household dysfunction, and HB traumas predicting symptoms of depression, anxiety, PTSD, dissociation, and sleep disturbance, and LB traumas predicting PTSD and dissociation symptoms. Native Hawaiian ethnicity and poorer socioeconomic status were predictive of greater trauma exposure and symptoms. Results suggest that more inclusive definitions of trauma are important for gender equity, and that ethnic group variation in symptoms is better explained by factors such as differential trauma exposure and economic and social status differences, rather than minority status per se.
\end{abstract}

Keywords: betrayal trauma, ethnicity, gender, socioeconomic status, Hawaii

Hawaii ${ }^{1}$ is ethnically and culturally diverse, and identifiable differences exist among ethnic groups in terms of history and social/socioeconomic status (Okamura, 2008). Although a few studies have looked at specific ethnic groups in Hawaii with regard to trauma exposure and posttraumatic symptoms (Friedman, Schnurr, Sengupta, Holmes, \& Ashcraft, 2004; Kulkarni \& Pole, 2008), we are not aware of any research to date that broadly surveys these topics in relation to socioeconomic inequalities. The current study examines rates of trauma exposure among men and women within various ethnic groups represented in Hawaii. We aim to explore how exposure to different types of traumas relates to a range of posttraumatic symptoms, and how social context factors such as ethnic group social status and personal socioeconomic status have an impact on these relationships.

Ethnic group differences in terms of control of land, resources, and political power have been present in Hawaii at least since the middle of the 19th century (Mokuau \& Matsuoka, 1995). While the cultural landscape of Hawaii continues to evolve, relatively stable distinctions among ethnic groups have existed for the past

This article was published Online First August 20, 2012

Bridget Klest and Jennifer J. Freyd, Department of Psychology, University of Oregon; Melissa Ming Foynes, Psychology and VA National Center for PTSD, VA Boston Healthcare System, Boston, Massachusetts.

The authors thank the Hawaii Personality and Health Cohort members and research team for their contributions to this research, and particularly Sarah Hampson for her input on this project. This research is funded by a grant from the National Institute on Aging, AG20048 (PI: Sarah Hampson).

Correspondence concerning this article should be addressed to Bridget Klest, PhD, VA Puget Sound, 1660 South Columbian Way, Seattle, WA 98108. E-mail: bklest@gmail.com several decades with regard to socioeconomic status indicators (Okamura, 1990, 2008). On average, Caucasians, Japanese Americans, and Chinese Americans in Hawaii have higher incomes, more education, and better employment than do Samoans, Filipino Americans, and Native Hawaiians (Okamura, 1990, 2008). Research also indicates that Native Hawaiians are at greater risk of exposure to traumatic stress, which some authors suggest may be a result of their history as a colonized indigenous people (Mokuau \& Matsuoka, 1995).

It may be the case that men and women from different ethnic groups, with different historical and cultural contexts, are differentially exposed to particular types of trauma. In order to explore this possibility, the current study aimed to capture a full range of events that could be defined as traumatic. Therefore, exposure to traumas with a high degree of life-threat but lower level of betrayal (LB traumas, e.g., motor vehicle accidents), traumas with a high degree of betrayal (HB traumas, e.g., abuse), and neglect and household dysfunction, were all assessed. Although neglect and household dysfunction have frequently been left out of trauma research (Briere \& Scott, 2006), exposure to such events has been associated with patterns of distress similar to those observed following other types of traumas (Edwards, Holden, Felitti, \& Anda, 2003).

Additional support for the importance of assessing a broad range of potentially traumatic events when examining ethnic group similarities and differences in trauma exposure comes from the utility of this approach in research clarifying gender differences in trauma exposure (Goldberg \& Freyd, 2006). Most studies assessing ex-

\footnotetext{
${ }^{1}$ Although the local spelling is often "Hawai'i," here we use the federally recognized spelling (Hawaii), as it is more common in the mainland U.S. and internationally.
} 
posure to traumatic events find that men have higher overall rates of trauma exposure than women, or that men and women have roughly equal rates of exposure (Goldberg \& Freyd, 2006; Hatch \& Dohrenwend, 2007; Manson, Beals, Klein, \& Croy, 2005; Tolin \& Foa, 2008). However, men and women differ in terms of the types of trauma reported (Flett, Kazantzis, Long, MacDonald, \& Millar, 2004; Goldberg \& Freyd, 2006; Tolin \& Foa, 2008) and relationships to perpetrators (Goldberg \& Freyd, 2006). More specifically, women are more likely to report exposure to sexual assault and violence perpetrated by close others (HB traumas), while men are more likely to report exposure to traumatic accidents and assaults by strangers or acquaintances (LB traumas). Women are also consistently more likely than men to develop PTSD (Tolin \& Foa, 2008).

Most research finds that members of ethnic minority groups are more likely than majority groups to be exposed to a variety of both noninterpersonal traumas (e.g., disasters, motor vehicle accidents; Perilla, Norris, \& Lavizzo, 2002) and interpersonal traumas (e.g., child sexual assault, physical assault; Flett et al., 2004) and are more likely to experience symptoms following trauma (Perilla et al., 2002; Rheingold et al., 2004). Moreover, differential trauma exposure substantially contributes to ethnic differences in rates of PTSD following combat (Dohrenwend, Turner, Turse, LewisFernandez, \& Yager, 2008) and natural disasters (Perilla et al., 2002), as well as gender differences in rates of PTSD (Tolin \& Foa, 2008). In other words, exposure to different types of trauma (e.g., sexual assault vs. accidental trauma), as well as greater intensity of trauma (e.g., greater losses during disasters), significantly contributes to gender and ethnic group differences in posttraumatic symptoms.

Asian Americans comprise one ethnic minority group that has been relatively understudied with regard to trauma exposure (Kulkarni \& Pole, 2008). In the few studies that do examine this population, Asian Americans are often treated as a homogenous ethnic group despite heterogeneity in history and cultural values of various Asian American groups. However, one study found that exposure to trauma and PTSD symptoms were least common among Japanese Americans, and most common among Native Hawaiians, with Caucasians falling in the middle (Friedman et al., 2004). In terms of historical context, Native Hawaiians may have more in common with other colonized indigenous groups, such as Native Americans, than with other Asian groups. Native Americans report high rates of trauma exposure, and differ from other ethnic groups in that both men and women report high rates of certain HB traumas (Manson et al., 2005; Koss et al., 2003). The fact that rates of trauma exposure and posttraumatic symptoms vary among ethnic groups and across genders, suggests that cultural and social factors influence these variables. Thus, social context theories, which implicate characteristics of the social environment in explaining group differences in symptom development, are particularly useful in providing a framework for examining the interrelationships among these constructs. Betrayal trauma theory (Freyd, 1996), for example, suggests that the social environment in which a traumatic event occurs, (e.g., in the context of a dependent relationship) has implications for how a victim will respond, and the types of posttraumatic symptoms that are likely to develop. Other social context factors including socioeconomic status, experiences of discrimination, personal or political power, treatment by others of higher status groups, educational attainment, and social support have all been implicated in either exposure to trauma, development of psychological symptoms, or both (Bonanno, Galea, Bucciarelli, \& Vlahov, 2007; Breslau et al., 1998; Gill \& Page, 2006; Manson et al., 2005; Perilla et al., 2002; Wilson, Rosenthal, \& Battle, 2007).

Given the existence of long-standing differences among ethnic groups in Hawaii with regard to many of these factors (Mokuau \& Matsuoka, 1995; Okamura, 2008), as well as the aforementioned research on gender and ethnic differences in trauma symptoms and exposure, we hypothesized several interrelations among trauma exposure, posttraumatic symptoms, socioeconomic status indicators, gender, and ethnicity in our Hawaiian sample. Based on prior research findings (e.g., Goldberg \& Freyd, 2006), we hypothesized that women would report more exposure to traumas with a high degree of betrayal (HB traumas) and men would report more exposure to traumas with no betrayal or lesser degrees of betrayal (LB traumas). We also predicted that socially disadvantaged groups (e.g., Native Hawaiians) would report more trauma exposure than dominant groups (e.g., Caucasians), as socioeconomic factors such as poor living environment have been implicated in exposure to multiple types of trauma (e.g., Dohrenwend et al., 2008; Perilla et al., 2002). We predicted that fewer gender differences in type of trauma exposure would exist for Native Hawaiians, related to prior findings of high rates of exposure to abuse traumas in both men and women in other native populations (e.g., Flett et al., 2004; Koss et al., 2003). We additionally predicted that similar patterns would exist for neglect and household dysfunction, as although such events have often not been classified as traumatic, they share many characteristics with high betrayal trauma events.

Based on the theory that social context significantly impacts response to trauma (e.g., Dohrenwend et al., 2008), we predicted that socioeconomic status of oneself and one's ethnic group would be negatively associated with mental health symptoms, and that trauma exposure (particularly HB traumas), would be positively associated with symptoms. Given the possible psychosocial impact of discrimination and historical colonization (e.g., Mokuau \& Matsuoka, 1995), we hypothesized that ethnic group social status would contribute significantly to prediction of symptoms over and above the contributions of trauma exposure and personal socioeconomic status.

\section{Method}

\section{Participants}

The Hawaii Personality and Health cohort is a group of adults who were rated in a study of personality characteristics when they were elementary schoolchildren in Hawaii between 1959 and 1967 (see Hampson et al., 2001 for more information). Members of this cohort were recontacted beginning in 1999, and approximately $60 \%$ of the original cohort members have responded to one or more of five sets of mailed questionnaires since that time (see Hampson et al., 2001, for a description of the history of this project). Eight-hundred and 33 cohort members responded to the most recent survey, mailed in May, 2008, and were included in the current study.

In the current study, $47 \%$ of participants were men and $53 \%$ were women, with an age range of 51 to 60 years $(M=55.05$, $S D=2.00)$. At the time they were surveyed, most participants 
were married $(65.7 \%)$, identified as heterosexual $(93.9 \%)$, had received at least some college or technical training $(80.9 \%)$, and were employed for wages or self-employed (78.1\%). Participants in this sample reported broad diversity in cultural group identification (35.5\% Japanese, 20.5\% Caucasian, 18.7\% Hawaiian, 9.2\% Filipino, 5.9\% Chinese, $4.2 \%$ Okinawan, $2.9 \%$ Latino, $0.8 \%$ Korean, $0.5 \%$ Other Pacific Islander, and 1.8\% "other"). At some point in their lifetimes, $11.3 \%$ of participants reported having served in the military.

\section{Measures}

Demographic information. Self-reported ethnic group identification was assessed with a single question ("Which group best describes your cultural identity?"), and the instruction to participants was to choose only one group with which they most strongly identified. Participants were asked whether they were employed for wages, self-employed, out of work for more than one year, out of work for less than one year, homemaker, student, retired, and/or permanently disabled/unable to work. Data regarding median income (family and individual), educational attainment, and fulltime and part-time employment status for different ethnic groups within Hawaii were obtained from the U.S. Census Bureau (U.S. Census Bureau, 2000).

Trauma Symptom Checklist-40 (TSC-40, Elliott \& Briere, 1992). The TSC-40 is a 40 -item checklist, assessing symptoms commonly associated with the experience of traumatic events, with higher scores indicating more symptoms. Respondents are asked to indicate how frequently they have experienced each symptom on a scale of 1 (never) to 4 (very often). The TSC-40 is composed of six symptom subscales: anxiety, depression, dissociation, sexual abuse trauma index, sexual problems, and sleep disturbances. The TSC-40 demonstrates good reliability and validity in samples of adults (Briere \& Runtz, 1989; Elliott \& Briere, 1992). Items related to sexual functioning and self-harm were removed in order to limit the number of sensitive questions included in the survey as a whole, generating a total of 30 items. All items required to compute subscale scores were included, with the exception of two depression subscale items. The TSC was scored by summing responses and total scores ranged from 30 to 120 .

PTSD Checklist-Civilian Version (PCL-C, Weathers, Huska, \& Keane, 1991). The PCL-C is a 17 -item self-report measure of PTSD symptoms. Respondents rate how often they have experienced each symptom, from 1 (not at all) to 5 (extremely), with higher scores indicating more symptoms (possible range of scores is 17 to 85 ). In the present study, the PCL-C was scored by summing responses. This measure demonstrates good reliability over time and is highly predictive of meeting criteria for DSM-IV defined PTSD (Norris \& Hamblen, 2004). Symptom reports on this measure are highly correlated with trauma exposure and other posttraumatic symptoms (Norris \& Hamblen, 2004).

Brief Betrayal Trauma Survey (BBTS; Goldberg \& Freyd, 2006). The BBTS is a self-report measure of trauma exposure. In the current version, respondents were asked to indicate whether (e.g., "yes," "no," "don't know/can't remember," and "decline to respond"), and how frequently (e.g., "never," "one or two times," "more than that") they experienced each of the 14 types of traumatic events surveyed before age 12, between ages 12 and 17, and at age 18 and over (see Freyd, 2008). The BBTS includes a variety of types of traumatic events, ranging from traumas without a betrayal component (e.g., exposure to accidental fire, flood, etc.), to traumas with a very high degree of betrayal (e.g., physical or sexual assault perpetrated by someone close to the victim). The BBTS describes events behaviorally instead of using labels such as "abuse." This measure is comparable to other trauma exposure measures in terms of reliability across time, and with regard to rates of trauma exposure observed in community samples (DePrince, 2001; Goldberg \& Freyd, 2006). Scores on this measure were computed by summing the number of "yes" responses, and subscale scores were computed for the number of types of events involving less betrayal (LB), and more betrayal (HB), reported by each participant.

Neglect and household dysfunction. The three items assessing neglect and household dysfunction were modeled after items from the Adverse Childhood Experiences study (Felitti et al., 1998) and were as follows: (a) Someone in your household was a problem drinker or alcoholic, or used street drugs, or was depressed or mentally ill, or attempted suicide, or went to prison; (b) No one in your family loved you or thought you were important or special, or your family didn't feel close to each other, or support each other; and (c) You didn't have enough to eat, or had to wear dirty clothes, or had no one to protect you, or your parents were too drunk or high to take care of you. Endorsement of similar items has been shown to predict physical and mental health problems in large samples of adult participants (Edwards et al., 2003; Felitti et al., 1998).

\section{Data Collection}

The Institutional Review Boards of the Oregon Research Institute and the Kaiser Permanente Center for Health Research, Hawaii, provided ethical approval for all data collection and analysis phased of this research, consistent with requirements for National Institutes of Health funded research. Written consent was obtained from all participants during each wave of the study.

Survey packets were mailed to participants' home addresses along with a cover letter and a postage-paid return envelope. One month after the initial mailing, a reminder letter was mailed. One month following the dispatch of reminder letters, duplicate packets were mailed to participants who had not yet responded. Participants who returned a completed survey were mailed a "thank you" letter and a $\$ 25$ check.

\section{Results}

\section{Data Preparation}

All analyses in this study were conducted using SPSS, with the exception of multilevel models which were conducted using HLM 6.06. Missing responses from items assessing demographic information and from measures of trauma exposure (e.g., BBTS and neglect/household dysfunction) were left as missing. For the TSC and PCL-C, a two-way imputation model was used to impute missing values (Sijtsma \& van der Ark, 2003; van Ginkel \& van der Ark, 2005). Less than 5\% of data points for each measure were missing initially, and missing values were spread relatively randomly across items and participants. Prior to replacing missing values for a given questionnaire, individuals with less than $66 \%$ 
valid responses to that questionnaire were excluded. For each analysis, all participants with sufficient data were included. A total of 724 participants had complete data for all measures, though some analyses using fewer measures included more participants.

Demographic variables coded for use in further analyses included gender (i.e., male, female), educational attainment, and work status. Educational attainment was scored by ranking response categories from the least to most education. Work status was scored by categorizing participants as working for pay versus not working.

Ethnic group categories used in the current study did not match perfectly with data available from the U.S. census. Thus, participants identifying as Okinawan $(N=33)$ and as Japanese American $(N=281)$ were combined into one group to match the U.S. Census Japanese category. Participants identifying as Other Pacific Islander $(N=4)$ were added to the Native Hawaiian group $(N=$ 148) to match the Native Hawaiian/Pacific Islander U.S. Census category.

\section{Descriptive Statistics}

A majority (78.4\%) of participants reported exposure to one or more traumatic events. More participants reported exposure to traumas low in betrayal $(68.1 \%)$ than to traumas with more betrayal $(47.8 \%)$, and $45.3 \%$ of participants reported experiencing some form of neglect or household dysfunction. When BBTS and neglect/household dysfunction items were combined into one variable to assess overall rates of trauma exposure, $83.1 \%$ of participants reported exposure to at least one traumatic event.

\section{Gender, Ethnicity, and Trauma Exposure}

Four independent samples $t$ tests were conducted to assess gender differences in trauma exposure. There were no significant differences observed between men and women in overall rates of trauma exposure (e.g., total BBTS score), $t(811)=-0.46, p=$ .64. Men reported more exposure to LB traumas $(M=2.70, S D=$ 3.18) than women $(M=2.05, S D=2.57), t(811)=-3.22, p<$ .01 , while women reported more exposure to HB traumas $(M=$ $1.86, S D=2.56)$ than $\operatorname{men}(M=1.48, S D=2.61), t(811)=2.12$, $p<.05$. Women also reported more household dysfunction exposure $(M=1.19 S D=1.56)$ than men $(M=0.88, S D=1.38)$, $t(780)=2.88, p<.01$.

Ethnic group differences in trauma exposure were assessed via a series of one-way ANOVAs. Participants identifying as Korean American $(n=6)$ and "other" $(n=14)$ were excluded from analyses due to small sample sizes. Significant ethnic group differences were found for exposure to HB, $F(5,765)=20.36, p<$ .001 and LB traumas, $F(5,765)=14.56, p<.001$, as well as overall trauma exposure, $F(5,765)=19.49, p<.001$. Post hoc pairwise comparisons revealed that these effects were completely accounted for by the fact that Native Hawaiians reported significantly more trauma exposure than all other groups, with the exception of Latinos, who did not differ significantly from any group. Significant ethnic group differences were also observed in exposure to neglect and household dysfunction, $F(5,738)=12.92$, $p<.001$. Pairwise post hoc comparisons revealed that Native Hawaiians and Caucasians both reported significantly more exposure than Japanese Americans or Chinese Americans, and Latinos reported significantly more exposure than Chinese Americans. Filipino Americans were not significantly different from any other group in exposure to neglect and household dysfunction.

Simple effects tests were conducted to test the hypothesis that Native Hawaiians have fewer gender differences in trauma exposure than other groups. Although the mean exposure to LB traumas was higher for Native Hawaiian men than women, this difference was not significant, $F(1,765)=0.82, p=.36$, while non-Native Hawaiian men reported significantly more exposure than women, $F(1,765)=12.09, p<.01$. Similarly, for HB traumas, Native Hawaiian men and women did not differ in exposure, $F(1,765)=$ $0.16, p=.69$, but non-Native Hawaiian women reported more exposure than men, $F(1,765)=4.47, p<.05$. Trauma exposure rates by gender and ethnicity are summarized in Figures 1 and 2 .

One-way ANOVA analyses were run using ethnicity as the grouping factor and each symptom measure as a separate dependent variable. Marginally significant ethnic group differences were observed for PTSD symptoms, and significant ethnic group differences were detected for dissociation, $F(5,765)=5.33, p<$ .001 , depression, $F(5,765)=2.64, p<.05$, anxiety, $F(5,765)=$ $5.04, p<.001$, and sleep problems, $F(5,765)=2.40, p<.05$. Post hoc tests using Tukey's HSD suggested more symptoms in general for Latino and Hawaiian participants, and fewer symptoms for Japanese, Caucasian, and Chinese participants. Filipino participants were not significantly different from any other group on any symptom measure.

\section{Trauma, Symptoms, and Social Resources}

Exposure to LB traumas, HB traumas, and neglect and household dysfunction, as well as gender, educational attainment, and work status, were entered as predictors of mental health symptoms

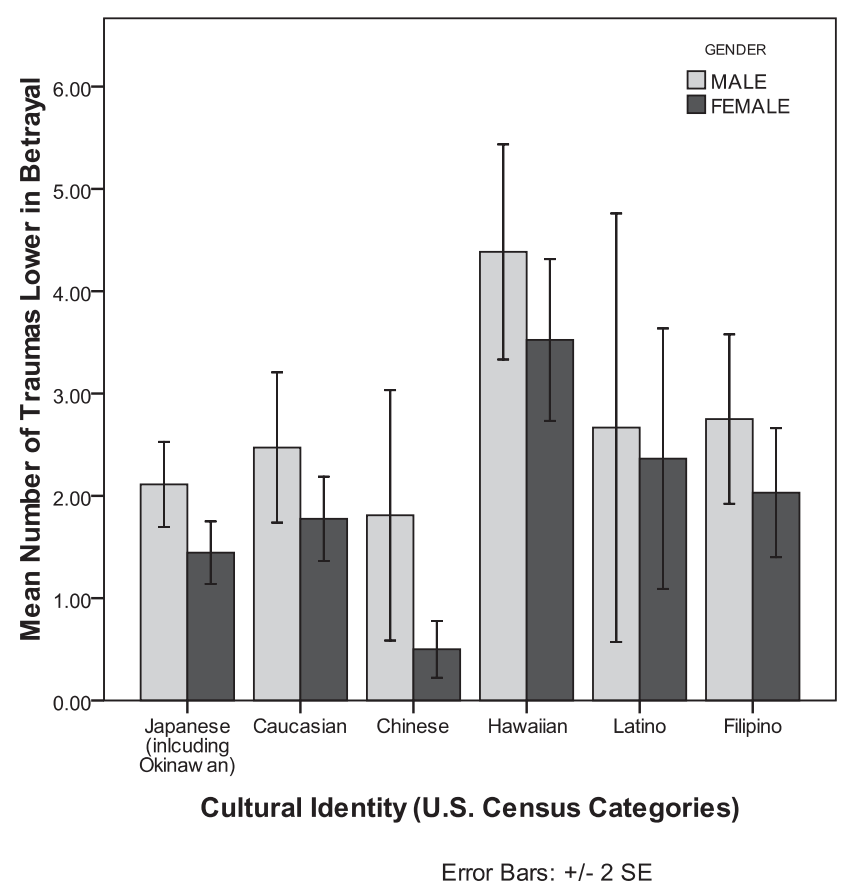

Figure 1. Exposure to Lower-Betrayal (LB) Traumas by Gender and Ethnicity. 


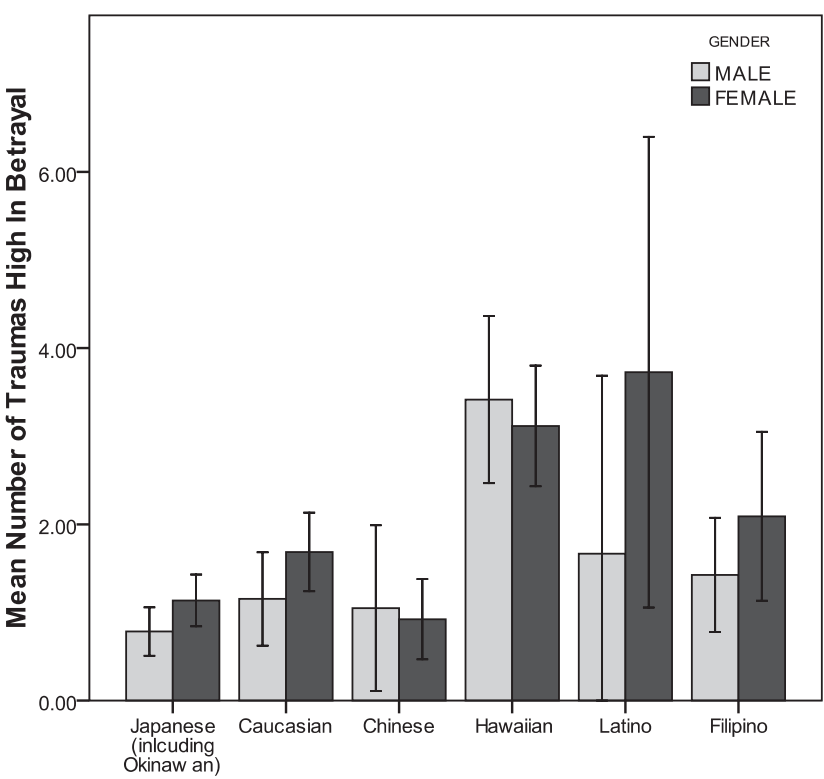

Cultural Identity (U.S. Census Categories)

Error Bars: +/- 2 SE

Figure 2. Exposure to High-Betrayal (HB) Traumas by Gender and Ethnicity.

in a series of regression models. HB traumas and neglect and household dysfunction were significant predictors of all outcomes, and LB traumas contributed significantly only to prediction of PTSD and dissociative symptoms, such that more exposure to trauma predicted more symptoms.

Gender significantly predicted symptoms of depression and anxiety, such that women reported more symptoms than men. Educational attainment was a significant predictor of symptoms of PTSD, dissociation, and anxiety, such that less education was associated with more symptoms. Work status was significantly associated with all outcome measures except dissociation, such that individuals who reported being engaged in work for pay reported fewer symptoms than those not employed for pay. See Table 1 for a summary of these results.

Ethnic group social status was computed using U.S. census data for income and educational attainment for each ethnic group. Regardless of method of computation, Japanese Americans, Cau- casians, and Chinese Americans had higher social status than Native Hawaiians, Filipino Americans, and Latinos.

Using the statistical modeling program HLM 6.06, student edition, a series of multilevel models was run in which individuals were nested within ethnic groups. Cases with missing data for one or more measures were deleted prior to creation of the multilevel data file $(n=724)$. Predictors entered at the level of the individual (level 1) included HB traumas, LB traumas, educational attainment, and work status. Ethnic group social status (e.g., higher vs. lower social status) was entered at the ethnic group level (level 2). A series of model comparisons was conducted, comparing the empty model to models using only level 1 predictors, only level 2 predictors, and both level 1 and level 2 predictors. Ethnic group social status significantly predicted PTSD symptoms but no other mental health outcomes. The results of these model tests are summarized in Table 2.

Intercept coefficients for the empty models indicated marginally significant variability among ethnic groups on the PCL-C, and significant ethnic group level variability for all other symptom measures. Coefficients for the best-fitting predictor models were also assessed. With the exception of dissociation, $p<.10$, no significant ethnic group differences in symptoms were found after accounting for the contribution of level-1 predictors. The only significant ethnic group differences were found in the relationship between traumas lower in betrayal and dissociation, though this did not relate in any way to social status. These results are summarized in Table 3.

\section{Discussion}

As predicted, although there were no statistically significant gender differences in overall number of traumas reported, women reported significantly more exposure to $\mathrm{HB}$ traumas and men reported more exposure to $\mathrm{LB}$ traumas. These results replicate the findings of Goldberg and Freyd (2006) and extend them to a more ethnically diverse sample. However, among Native Hawaiian participants, men and women both reported high levels of exposure to HB traumas, and although men reported more LB trauma exposure, there were no statistically significant gender differences. This pattern is consistent with findings from research on other colonized indigenous groups (Flett et al., 2004; Manson et al., 2005), and points to the importance of distinguishing among different "Asian American" populations, with different historical experiences, in trauma research.

Table 1

Trauma, Gender, Social Resources, and Mental Health Symptoms

\begin{tabular}{|c|c|c|c|c|c|c|c|c|}
\hline \multirow[b]{2}{*}{ Dependent measure } & \multirow[b]{2}{*}{$R$} & \multirow[b]{2}{*}{$F$} & \multicolumn{6}{|c|}{ Semi-partial $r$} \\
\hline & & & $\begin{array}{l}\text { Traumas lower } \\
\text { in betrayal }\end{array}$ & $\begin{array}{l}\text { Traumas high } \\
\text { in betrayal }\end{array}$ & $\begin{array}{l}\text { Neglect \& household } \\
\text { dysfunction }\end{array}$ & Gender & $\begin{array}{c}\text { Educational } \\
\text { attainment }\end{array}$ & Work status \\
\hline PCL-C PTSD & .44 & $29.61^{* * * *}$ & $.11^{* * *}$ & $.11^{* * *}$ & $.16^{* * * *}$ & -.05 & $-.09^{*}$ & $.07^{*}$ \\
\hline TSC dissociation & .44 & $29.54^{* * * *}$ & $.10^{\text {** }}$ & $.13^{* * * *}$ & $.12^{* * * *}$ & .06 & $-.12^{* * * *}$ & .06 \\
\hline TSC depression & .42 & $27.01^{* * * *}$ & .01 & $.16^{* * * *}$ & $.15^{* * * * *}$ & $.13^{* * * *}$ & -.05 & $.07^{*}$ \\
\hline TSC anxiety & .44 & $30.45^{* * * *}$ & $.07^{+}$ & $.12^{* * * * *}$ & $.14^{* * * *}$ & $.12^{* * * *}$ & $-.13^{* * * *}$ & $.10^{* * *}$ \\
\hline TSC sleep problems & .37 & $19.66^{* * * *}$ & .02 & $.12^{* * * *}$ & $.14^{* * * *}$ & .06 & -.06 & $.09^{* *}$ \\
\hline
\end{tabular}

Note. $\quad d f=6,754$.

${ }^{+} p<.10 .^{*} p<.05 . \quad{ }^{* *} p<.01 .^{* * *} p<.001$. 
Table 2

Deviance Tests of Nested Models

\begin{tabular}{|c|c|c|c|}
\hline & 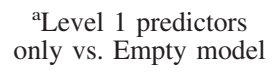 & $\begin{array}{l}\text { bLevel } 2 \text { predictors } \\
\text { only vs. Empty model }\end{array}$ & $\begin{array}{l}{ }^{\mathrm{a}} \text { Level } 1 \text { and }{ }^{\mathrm{b}} \text { Level } 2 \text { predictors } \\
\text { vs. }{ }^{\mathrm{a}} \text { Level } 1 \text { predictors only }\end{array}$ \\
\hline Outcome variable & $\chi^{2}(d f=14)$ & $\chi^{2}(d f=1)$ & $\chi^{2}(d f=1)$ \\
\hline PCL-C PTSD & $135.22^{* * * *}$ & $3.88^{*}$ & $4.29^{*}$ \\
\hline TSC dissociation & $127.77^{* * * * *}$ & $3.67^{+}$ & $\mathrm{n} / \mathrm{a}^{\mathrm{c}}$ \\
\hline TSC depression & $90.51^{* * * *}$ & 1.31 & $\mathrm{n} / \mathrm{a}^{\mathrm{c}}$ \\
\hline TSC anxiety & $119.48^{* * * *}$ & $2.98^{+}$ & $\mathrm{n} / \mathrm{a}^{\mathrm{c}}$ \\
\hline TSC sleep problems & $71.93^{* * * *}$ & 1.44 & $\mathrm{n} / \mathrm{a}^{\mathrm{c}}$ \\
\hline
\end{tabular}

In addition to reporting more exposure to HB traumas, women also reported more exposure to neglect and household dysfunction than did men. These results point to the need for inclusion of a full range of high betrayal events in definitions of trauma, if such definitions are to be gender equitable. Because men are more likely than women to report LB traumas, focusing primarily on this type of trauma may result in the appearance that men are exposed to more traumatic stressors than women.

As predicted, Native Hawaiians reported more trauma exposure than higher status groups, including Caucasians, Japanese Americans, and Chinese Americans. However, contrary to prediction, other lower status groups (Latinos, Filipino Americans) did not report more trauma exposure. Unfortunately, the relatively small sample-size for Latinos $(n=23)$ precludes drawing meaningful conclusions about this ethnic group from the analyses in this study; a larger sample size and more information about the cultural homogeneity of this group would be required to better understand

Table 3

Ethnic Group Variability in Symptoms, and in Associations Between Trauma and Symptoms

\begin{tabular}{lcc}
\hline & $\begin{array}{c}\text { Empty model } \\
\text { Outcome variable }\end{array}$ & $\begin{array}{c}\text { Best-fitting } \\
\text { predictor model }\end{array}$ \\
\cline { 2 - 3 } PCL-C & & \\
Intercept & $9.63^{+}$ & 7.22 \\
LB trauma & & 2.64 \\
HB trauma & & 3.10 \\
TSC dissociation & & \\
Intercept & $31.38^{* * *}$ & $10.03^{+}$ \\
LB trauma & & $19.15^{* *}$ \\
HB trauma & & 8.39 \\
TSC depression & & 6.32 \\
Intercept & $15.10^{* *}$ & 3.66 \\
LB trauma & & 3.73 \\
HB trauma & & 5.44 \\
TSC anxiety & & 4.04 \\
Intercept & $36.21^{* * *}$ & 6.35 \\
LB trauma & & 9.06 \\
HB trauma & & 4.59 \\
TSC sleep problems & & 7.27 \\
Intercept & $14.48^{*}$ & \\
LB trauma & & \\
HB trauma & & \\
\hline
\end{tabular}

${ }^{\mathrm{a}}$ Level 1 and 2 predictors for PCL-C, level 1 predictors only for all others. ${ }^{+} p<.10 .{ }^{*} p<.05 .{ }^{* * *} p<.01 .{ }^{* * * *} p<.001$. the findings. However, the fact that Native Hawaiians reported more trauma exposure than Filipino Americans (who have similar socioeconomic status), suggests that either the measures of social status used here (e.g., income and educational attainment) do not adequately capture the full range of variation in ethnic group social status, or that other factors beyond social status contribute to predicting trauma exposure. It is plausible that both of these possibilities are true. The historical context of colonization may put Native Hawaiians at particular risk, due to intergenerational transmission of historical trauma, experiences of racism, and related factors, in addition to the factors examined in the current study.

While the observed high rates of neglect and household dysfunction among Native Hawaiians was consistent with predictions, and consistent with findings for other types of traumas, elevated rate of these experiences among Caucasians was unexpected. One potential explanation is that Caucasians were simply more likely to identify with and report these experiences than the other Asian American groups surveyed. Although the items assessing neglect and household dysfunction in this study were behaviorally defined, which tends to reduce socially desirable responding (Meston, Heiman, Trapnell, \& Carlin, 1999), research also demonstrates that adherence to Asian cultural values (Foynes, Platt, Hall, \& Freyd, 2012) and cultural differences in labeling experiences as abuse (Lau et al., 2006), may impact disclosure of trauma.

Exposure to trauma was significantly associated with more mental health symptoms on all symptom measures used in this study. When controlling for gender, educational attainment, and employment status, HB traumas and neglect and household dysfunction each uniquely predicted variance in symptoms of anxiety, depression, and sleep disturbance, while LB traumas contributed to symptoms of dissociation and PTSD. That different types of traumas predict different symptom patterns supports a distinction between fear-based and betrayal-based traumatic stressors (Freyd, 1996). Furthermore, this pattern of results suggests that neglect and household dysfunction are similar to HB traumas in terms of symptom prediction. If this is true, then describing neglect and household dysfunction as traumatic, and possibly as involving context factors that mirror betrayal, may be warranted.

Although slightly different patterns of results were observed for each symptom measure, Native Hawaiians (and Latinos, though due to small sample size these findings should be interpreted cautiously) generally reported more symptoms than Japanese 
Americans, Caucasians, and Chinese Americans; Filipino American participants fell somewhere in between. Unexpectedly, Filipino Americans did not differ significantly from any other ethnic group on any measure of mental health symptoms, despite their lower socioeconomic status in Hawaii. As discussed above, it is possible that more subtle variations in social status, or other factors not measured in this study, contribute to symptoms.

When controlling for trauma exposure and gender, lower educational attainment predicted more symptoms of PTSD, dissociation, and anxiety, while being employed for pay predicted fewer symptoms of PTSD, depression, anxiety, and sleep disturbance. These results suggest that socioeconomic resources are significantly and negatively associated with mental health symptoms. Contrary to predictions, it was found that ethnic group social status was not associated with symptoms when controlling for trauma exposure, gender, and personal socioeconomic variables. In general, these results suggest that there is no direct effect of ethnic group social status on symptoms in most cases, and that personal access to resources predicts symptoms better than ethnic group social status. This could have implications for mental health treatment programs, in that efforts to improve educational access and employment may be an important part of treatment in disadvantaged populations.

Results should be interpreted in the context of several important limitations of this study. Unequal sample sizes among ethnic groups may have limited our ability to fully understand some results. In particular, we must be cautious in drawing conclusions about the Latino group in this study, due to greater variability and smaller sample size for this group. Generalizability of these results may also be limited by the specific age cohort of the sample and Hawaii's unique ethnic group and social stratification. Furthermore, this study relied entirely on self-report measures which may have resulted in biased responding. The correlational design of this study precludes making claims about the direction of causality in relationships among variables. Theoretically, we expect that many of these relationships are bidirectional, and specifics of causality may be difficult to untangle.

This study adds new information about the prevalence of traumatic stress and mental health symptoms across ethnic groups in Hawaii. In addition, this study provides preliminary information on the independent contribution of neglect and household dysfunction to the prediction of symptoms, and begins to examine how such events might be classified with other forms of trauma. Results suggest that gender and ethnic group variation in symptoms is strongly associated with trauma exposure and personal access to socioeconomic resources. Therefore, it is recommended that trauma psychologists incorporate social context factors when considering the impact of traumatic stress.

\section{References}

Bonanno, G. A., Galea, S., Bucciarelli, A., \& Vlahov, D. (2007). What predicts psychological resilience after disaster? The role of demographics, resources, and life stress. Journal of Consulting and Clinical Psychology, 75, 671-682. doi:10.1037/0022-006X.75.5.671

Breslau, N., Kessler, R. C., Chilcoat, H. D., Schultz, L. R., Davis, G. C., \& Andreski, P. (1998). Trauma and posttraumatic stress disorder in the community: The 1996 Detroit Area Survey of Trauma. Archives of General Psychiatry, 55, 626-632. doi:10.1001/archpsyc.55.7.626
Briere, J., \& Runtz, M. (1989). The Trauma Symptom Checklist (TSC-33): Early data on a new scale. Journal of Interpersonal Violence, 4, 151163. doi:10.1177/088626089004002002

Briere, J., \& Scott, C. (2006). Principles of trauma therapy: A guide to symptoms, evaluation, and treatment. Thousand Oaks, CA: Sage Publications.

DePrince, A. P. (2001). Trauma and posttraumatic responses: An examination of fear and betrayal. Doctoral Dissertation, University of Oregon.

Dohrenwend, B. P., Turner, J. B., Turse, N. A., Lewis-Fernandez, R., \& Yager, T. J. (2008). War-related posttraumatic stress disorder in Black, Hispanic, and Majority White Vietnam veterans: The roles of exposure and vulnerability. Journal of Traumatic Stress, 21, 133-141. doi:10 $.1002 /$ jts. 20327

Edwards, V. J., Holden, G. W., Felitti, V. J., \& Anda, R. F. (2003). Relationship between multiple forms of childhood maltreatment and adult mental health in community respondents: Results from the adverse childhood experiences study. American Journal of Psychiatry, 160, 1453-1460. doi:10.1176/appi.ajp.160.8.1453

Elliott, D. M., \& Briere, J. (1992). Sexual abuse trauma among professional women: Validating the Trauma Symptom Checklist-40 (TSC-40). Child Abuse \& Neglect, 16, 391-398. doi:10.1016/0145-2134(92)90048-V

Felitti, V. J., Anda, R. F., Nordenberg, D., Williamson, D. F., Spitz, A. M., Edwards, V., . . Marks, J. S. (1998). Relationship of childhood abuse and household dysfunction to many of the leading causes of death in adults: The Adverse Childhood Experiences (ACE) Study. American Journal of Preventive Medicine, 14, 245-258. doi:10.1016/S07493797(98)00017-8

Flett, R. A., Kazantzis, N., Long, N. R., MacDonald, C., \& Millar, M. (2004). Gender and ethnicity differences in the prevalence of traumatic events: Evidence from a New Zealand community sample. Stress \& Health: Journal of the International Society for the Investigation of Stress, 20, 149-157. doi:10.1002/smi.1014

Foynes, M. M., Platt, M., Hall, G. N., \& Freyd, J. J. (2012). The impact of Asian values and victim-perpetrator closeness on the disclosure of emotional, physical, and sexual trauma. Manuscript submitted for publication.

Freyd, J. J. (1996). Betrayal trauma: The logic of forgetting childhood abuse. Cambridge, MA: Harvard University Press.

Freyd, J. J. (2008). Brief Betrayal Trauma Survey (BBTS). Retrieved March 16, 2009, from http://dynamic.uoregon.edu/ jjf/bbts/

Friedman, M. J., Schnurr, P. P., Sengupta, A., Holmes, T., \& Ashcraft, M. (2004). The Hawaii Vietnam Veterans Project: Is minority status a risk factor for posttraumatic stress disorder? Journal of Nervous and Mental Disease, 192, 42-50. doi:10.1097/01.nmd.0000105999.57129.ee

Gill, J., \& Page, G. (2006). Psychiatric and physical health ramifications of traumatic events in women. Issues in Mental Health Nursing, 27, 711734. doi:10.1080/01612840600781121

Goldberg, L. R., \& Freyd, J. J. (2006). Self-reports of potentially traumatic experiences in an adult community sample: Gender differences and test-retest stabilities of the items in a brief betrayal-trauma survey. Journal of Trauma \& Dissociation, 7, 39-63. doi:10.1300/ J229v07n03_04

Hampson, S. E., Dubanoski, J. P., Hamada, W., Marsella, A. J., Matsukawa, J., \& Suarez, E. (2001). Where are they now? Locating former elementary-school students after nearly 40 years for a longitudinal study of personality and health. Journal of Research in Personality, 35, 375 387.

Hatch, S. L., \& Dohrenwend, B. P. (2007). Distribution of traumatic and other stressful life events by race/ethnicity, gender, SES and age: A review of the research. American Journal of Community Psychology, 40, 313-332. doi:10.1007/s10464-007-9134-Z

Koss, M. P., Yuan, N. P., Dightman, D., Prince, R. J., Polacca, M., Sanderson, B., \& Goldman, D. (2003). Adverse childhood exposures and alcohol dependence among seven Native American tribes. American 
Journal of Preventive Medicine, 25, 238-244. doi:10.1016/S07493797(03)00195-8

Kulkarni, M., \& Pole, N. (2008). Psychiatric distress among Asian and European American survivors of the 1994 Northridge earthquake. Journal of Nervous and Mental Disease, 196, 597-604. doi:10.1097/NMD $.0 \mathrm{~b} 013 \mathrm{e} 3181813290$

Lau, A. S., Huang, M. M., Garland, A. F., McCabe, K. M., Yeh, M., \& Hough, R. L. (2006). Racial variation in self-labeled child abuse and associated internalizing symptoms among adolescents who are high risk. Child Maltreatment, 11, 168-181. doi:10.1177/1077559505285776

Manson, S. M., Beals, J., Klein, S. A., \& Croy, C. D. (2005). Social epidemiology of trauma among 2 American Indian reservation populations. American Journal of Public Health, 95, 851-859. doi:10.2105/ AJPH.2004.054171

Meston, C. M., Heiman, J. R., Trapnell, P. D., \& Carlin, A. S. (1999). Ethnicity, desirable responding, and self-reports of abuse: A comparison of European- and Asian-ancestry undergraduates. Journal of Consulting and Clinical Psychology, 67, 139-144. doi:10.1037/0022-006X.67.1 .139

Mokuau, N., \& Matsuoka, J. (1995). Turbulence among a Native People: Social work practice with Hawaiians. Social Work, 40, 465-472. doi: 10.1093/sw/40.4.465

Norris, F. H., \& Hamblen, J. L. (2004). Standardized self-report measures of civilian trauma and PTSD. In J. P. Wilson \& T. M. Keane (Eds.), Assessing psychological trauma and PTSD (2nd ed., pp. 63-102). New York, NY: Guilford Press.

Okamura, J. Y. (1990). Ethnicity and stratification in Hawaii. Honolulu, HI: Resource Papers. Retrieved from http://www.eric.ed.gov/ERIC WebPortal/contentdelivery/servlet/ERICServlet?accno $=$ ED347220

Okamura, J. Y. (2008). Ethnicity and inequality in Hawai'i. Asian American history and culture. Philadelphia, PA: Temple University Press.
Perilla, J., Norris, F. H., \& Lavizzo, E. A. (2002). Ethnicity, culture, and disaster response: Identifying and explaining ethnic differences in PTSD six months after Hurricane Andrew. Journal of Social and Clinical Psychology, 21, 20-45. doi:10.1521/jscp.21.1.20.22404

Rheingold, A. A., Smith, D. W., Ruggiero, K. J., Saunders, B. E., Kilpatrick, D. G., \& Resnick, H. S. (2004). Loss, trauma exposure, and mental health in a representative sample of 12-17-year-old youth: Data from the National Survey of Adolescents. Journal of Loss \& Trauma, 9(1), 1-19. doi:10.1080/15325020490255250

Sijtsma, K., \& van der Ark, L. A. (2003). Investigation and treatment of missing item scores in test and questionnaire data. Multivariate Behavioral Research, 38, 505-528. doi:10.1207/s15327906mbr3804_4

Tolin, D. F., \& Foa, E. B. (2008). Sex differences in trauma and posttraumatic stress disorder: A quantitative review of 25 years of research. Psychological Trauma: Theory, Research, Practice, and Policy, S, 3785. doi:10.1037/1942-9681.S.1.37

U.S. Census Bureau. (2000). United States-Data Sets-American FactFinder. Retrieved March 25, 2009, from http://factfinder.census.gov/ servlet/DatasetMainPageServlet?

van Ginkel, J. R., \& van der Ark, L. A. (2005). SPSS syntax for missing value imputation in test and questionnaire data. Applied Psychological Measurement, 29, 152-153. doi:10.1177/0146621603260688

Weathers, F. W., Huska, J. A., \& Keane, T. M. (1991). PCL-C for DSM-IV Boston, MA: National Center for PTSD-Behavioral Science Division.

Wilson, W. C., Rosenthal, B. S., \& Battle, W. S. (2007). Effects of gender, ethnicity and educational status on exposure to community violence and psychological distress in adolescence. Journal of Aggression, Maltreatment \& Trauma, 15, 93-111. doi:10.1300/J146v15n01_06

Received July 6, 2011

Revision received April 4, 2012 Accepted April 29, 2012 